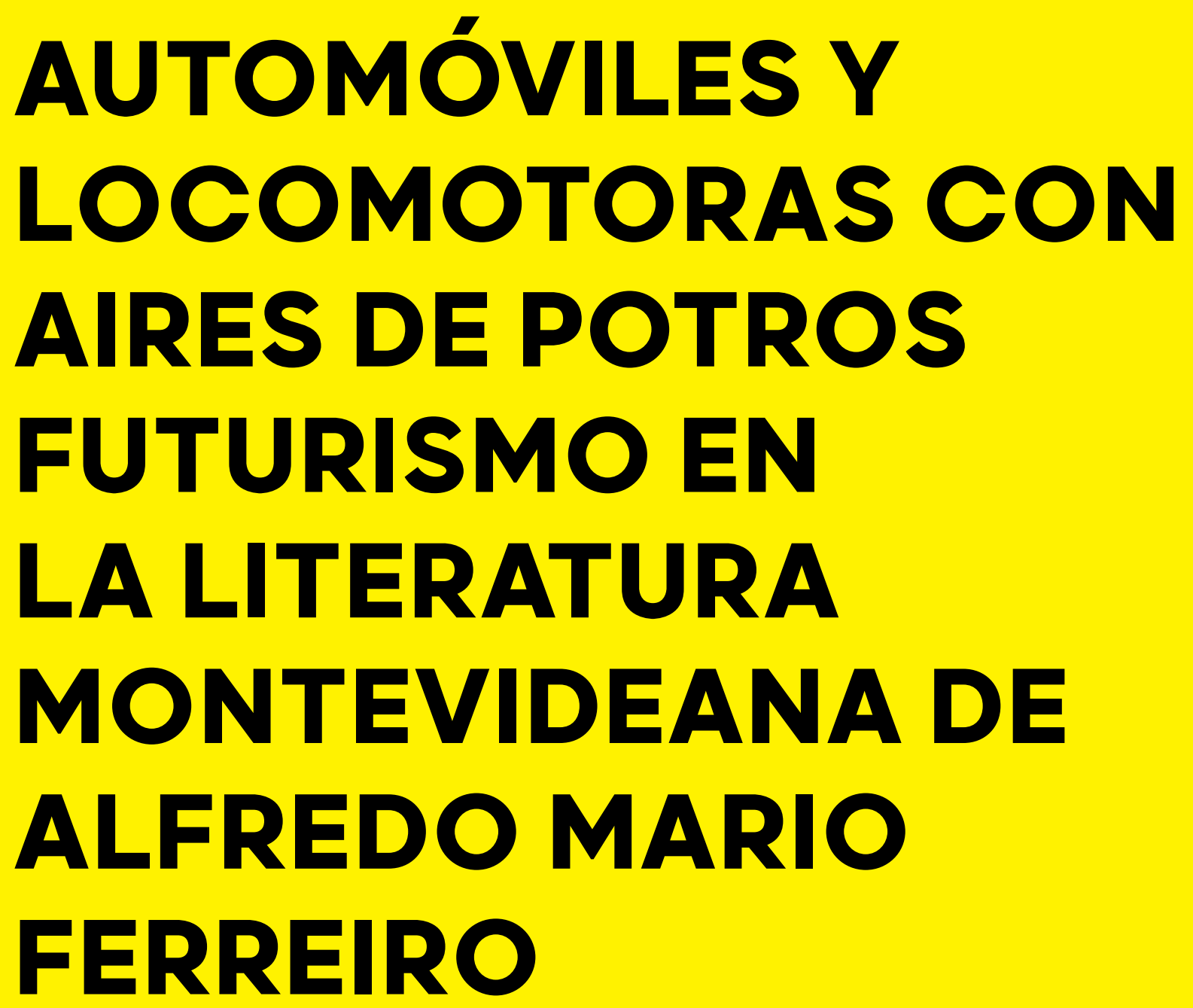

Automobiles and locomotives with foals" airs. Futurism in Montevidean literature by Alfredo Mario Ferreiro

\title{
Verónica Cohen
}

ISSN (imp): 1390-4825

ISSN (e): 2477-9199

Fecha de recepción: 04/08/19

Fecha de aceptación: 05/22/19 


\section{Resumen:}

El poeta uruguayo Alfredo Mario Ferreiro escribe su primer libro El hombre que se comió un autobús (Poemas con olor a nafta) en 1927. Un año antes, Tomasso Marinetti, creador del movimiento futurista, había visitado Río de la Plata como parte de una gira latinoamericana. La obra de Ferreiro está influenciada por este movimiento, pero en un análisis más profundo de sus obras, deja en evidencia que, al ser "replicado" en América, aparece un futurismo con nuevos elementos, donde"lo vital"(Kush, 1986, pp.6-10) se hace presente. Nos interesa abordar a este artista como caso para mostrar que, como siempre, la apropiación de lo europeo en América involucra la aparición de elementos propios que requieren que el análisis sobrepase la forma.

\section{Palabras clave:}

Alfredo Mario Ferreiro, futurismo, literatura, America Latina, apropiación, vital

\section{Abstract:}

Alfredo Mario Ferreiro, Uruguayan poet, writes his first book El hombre que se comió un autobús (Poemas con olor a nafta)/The man who ate a bus (Poems which smells as petrol), in 1927. A year earlier, Tomasso Marinetti, creator of the Futurist movement visited in Rio de la Plata as part of a Latin American tour. This movement influenced Ferrreiro's work, but an in-depth analysis of his works shows that even if it is being when being "reproduced" in America, a new type of futurism appears with different elements, where "the vital" (Kush, 1986: 6- 10) is present. This article approaches this artist as a case to show how American appropriation of the European always involves the presence elements that require an analysis that surpasses the form.

\section{Key Words:}

Alfredo Mario Ferreiro, futurism, literature, Latin American, appropriations, vital

\section{Biografía del autor:}

Verónica Cohen, 8 de marzo de 1986, es doctoranda en Historia y Teoría de las Artes, Universidad de Buenos Aires y en Centre d'Etudes des Arts Contemporains en la Universidad Lille du Nord, dirigida por Horacio Banega, Anne Boissère y Susana Tambutti, con beca de Conicet. Especialista en Lenguajes artísticos combinados, Universidad Nacional de las Artes. Licenciada y profesora en Ciencias de la Comunicación, en la Universidad de Buenos Aires. Cocreó Notaciones Abisales, plataforma editorial de traducción y performance. Se desempeña también como artista, especialmente en el ámbito de la danza y performance. 


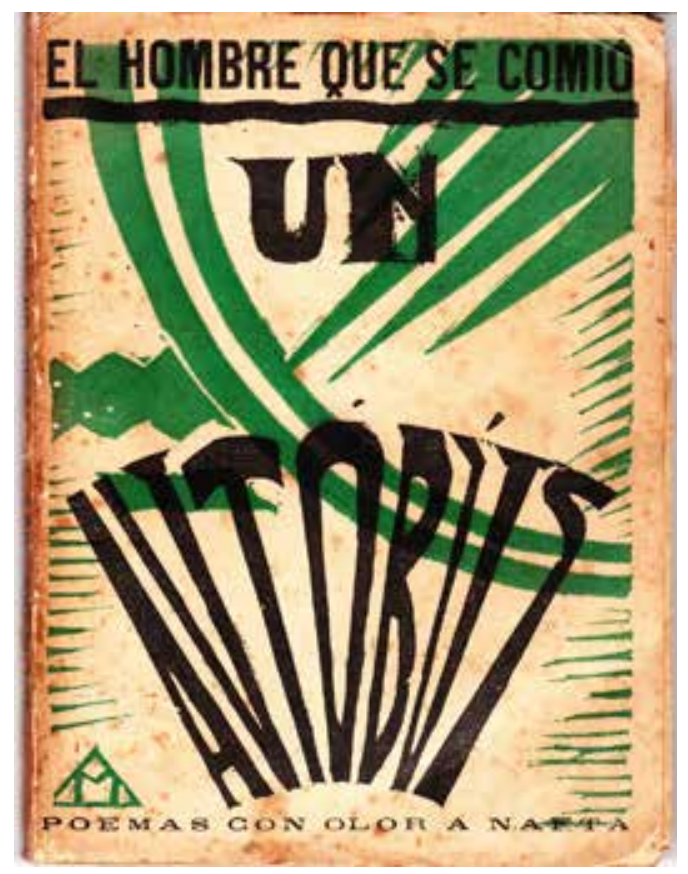

Figura 1. Portada de la edición original de El hombre que se comió un autobús (poemas con olor a nafta), editado por La

Cruz del Sur. Las ilustraciones de esta primera edición fueron realizadas por Renée Magariños, Señorita de Padilla, Melchor Méndez Magarińos y Gervasio Furest.

"Pero mientras en Occidente lo vital y lo formal mantienen una conexión dentro la ciudad y se resuelven simplemente por la expresión en el sentido de Klages, en América lo vital yace a extramuros, en el suburbio o en el interior, donde la presencia

del indio o del mestizo le agrega una dimensión telúrica difícilmente asimilable a la formalidad ciudadana. En América lo viviente pertenece al subsuelo social, se asocia a la negación de la ciudad...”

Roberto Kush

\section{Montevideo-Europa-Montevideo: ideas en movimiento}

\section{Afirmaba Jorge Luis Borges en la revista Sintesis} en el año 1927:

"Alfredo Mario Ferreiro es el único futurista que he conocido. No es, como el orador itálico Marinetti, un declamador de las máquinas ni un dominado por su envión o su rapidez; es un hombre que se alegra de que haya máquinas. También de que haya viento y potros y vidas. Es decir, la realidad le da gusto." (Borges, 1927, pp. 321-322)
Decido dar comienzo a este trabajo sobre Alfredo Mario Ferreiro con estas dos citas. La referencia a Borges considero refuerza el epígrafe de Kush. A finales de los años 20, el futurismo llegó desde Europa a la República Oriental del Uruguay, específicamente a un Montevideo en transformación, de automóviles, de los primeros rascacielos, de un clima de ciudad en aceleración, una ciudad en crecimiento, modernizándose. Las ideas del futurismo arribaron a la ciudad oriental de dos maneras: por un lado los viajes que los artistas hicieron a Europa para formarse donde hicieron que se relacionen con miembros de las vanguardias italianas, españolas y holandesas; por otro lado los de textos de Filipo Tomasso Marinetti, creador del movimiento, se conocieron a través de publicaciones en revistas, como, por ejemplo El Manifiesto Futurista apareció en Le Figaro, en Francia en 1909 y en 1915, y fue traducido al castellano en Valencia por Ramón Gómez de la Serna (Rocca, 2009, p.106). Entre las respuestas al manifiesto llama la atención la del poeta uruguayo-francés Álvaro Armando Vaseeur (1955, p. 259) quien en un poema critica a Marinetti y considera que le robó el término futurismo. En 1926, Marinetti visitó Brasil, Argentina y en Uruguay pasó dos días en Montevideo. Pablo Rocca remarcó que el interés de la extensa gira (dos meses y medio en total) estaba relacionada no solo a expandir el 
movimiento y "encontrar nuevos adeptos", sino también a "difundir las conexiones ideológicas entre futurismo y fascismo, y también fue una estupenda oportunidad para hacer buenos negocios” (Rocca, 2009, p.106). A Montevideo, el comité llegó el 6 de junio, luego de las repercusiones que tuvieron las conferencias en Brasil y Argentina, donde hubo enfrentamientos, se generaron polémicas, amores y odios, todo cubierto exhaustivamente por los medios de comunicación de la época. En Montevideo, Marinetti elige resaltar la figura del uruguayo Jules Laforge como precursor del futurismo. Esta elección da cuenta del cambio de Marinetti en esos años, ya que niega el clima rupturista con todo pasado del primer futurismo. Laforge, quien fue uno de los precursores del verso libre, aunque nacido en Montevideo, realizó toda su obra en Francia y en francés, por lo tanto, queda en duda si esta referencia era relevante para los artistas de la época como vínculo Uruguay-Europa.

En este trabajo me interesaré por el artista Alfredo Mario Ferreiro. Volviendo al epígrafe y la frase de Borges, no podemos decir que este autor es futurista al modo europeo, por lo que busco resaltar lo que ocurrió en el cruce entre lo europeo y lo americano y cómo en este cruce pueden ocurrir giros como el de la afirmación de Borges, en la que Ferreiro se convierte en el mejor futurista de los futuristas, mejor incluso que su creador, porque lo vital se hace presente en su amor por las máquinas. Entonces ¿qué es lo vital y cómo aparece?

\section{Vibrar: autobuses y potros}

“Tú y yo somos a semejanza de los motores maravillosos" "Potros

Pedacitos de escudo nacional Bellaqueando como una bandera.”

Alfredo Mario Ferreiro

Alfredo Mario Ferreiro fue poeta y periodista. Sus obras relacionadas con el futurismo son: sus dos libros de poesía publicados: El hombre que se comio un autobuis (Poemas con olor a nafta) (Ferreiro, 1969) (EHA de ahora en adelante) y Se ruega no dar la mano. Poemas profilácticos a base de imágenes esmeriladas (Ferreiro, 1930) (SRM de ahora en adelante); y sus colaboraciones en Vida Femenina Revista del hogar y la mujer (en Gropp, 2009), de 1927 a 1933.

Publicado un año después de la visita de Marinetti, el contexto en el que surge $E H A$ es, siguiendo al investigador Pablo Rocca (2009, pp.9-10), el momento de mayor publicaciones con ideas futuristas; ya que, además de este libro, se publicaron Palacio Salvo, de Juvenal Ortiz Saralegui, y Paracaídas, de Enrique Ricardo Garet. Todas las obras comparten entre sí la intención de seguir las tendencias de la vanguardias europeas y la aparición con fuerza tanto de la máquina como del nuevo paisaje montevideano.

La tapa del libro cuenta con un diseño futurista. La tipografía está en negro y evoca movimiento, por los diversos tamaños que tiene cada palabra, resalta "Autobús" por ser la única palabra que no mantiene la línea horizontal $y$, en cambio, se presenta en forma de abanico, con su letras estiradas. En el fondo, puntas verdes se secuencian a los costados de la página y en medio de ella, irrumpen los fragmentos de círculos ${ }^{1}$.

Esta publicación cuenta con una dedicatoria a su mujer que funciona casi como un manifiesto de acción. De allí, rescato el epígrafe que introduce este apartado: “Tú y yo somos a semejanza de los motores maravillosos". La referencia a las máquinas en general y al autobús en particular se evidencia en los títulos de los capítulos de la obra que son significantes referidos a sus partes: "radiador", “carburador", "diferencial”. La admiración a la máquina va a ser parte de toda la obra de Ferreiro. El recurso literario que da cuenta de esto es la personificación. Un ejemplo es "Poema del rascacielos de salvo", donde el rascacielo deviene en una jirafa:

"El rascacielos es una jirafa de cemento armado

con la piel manchada de ventanas.

Una jirafa un poco aburrida porque no han brotado palmeras de 100 metros.

1 En la reedición de 1969, no se utilizó esta portada, sino que se diseño otra donde la referencia es hacia los significados del texto, ya que en ella se muestra una silueta humana fucsia y, dentro de ella, en naranja y blanco a la altura de donde estaría el estómago, un autobús. La comparación entre las dos tapas me hacen reflexionar sobre la relación entre lenguaje verbal y visual y cómo, en el caso de la publicación de 1927, se priorizó la relación a través de lo significante más que lo significado, ya que el ritmo de las líneas y los contrastes de colores refieren más a la forma de los poemas que componen el libro que a los significados "hombre", "comer", "autobús". 
POEMA SIN OBSTACULOS DEL TRANSITO LIGERO

VOITURETTE,

LIMOUSINE,

DOBLE-PHAETON,

UN CAMION,

20 TAXIS

8 MOTOS,

2 TRANVIAS,

AUTOBUS.

Agente de tránsito
Todo en paz.

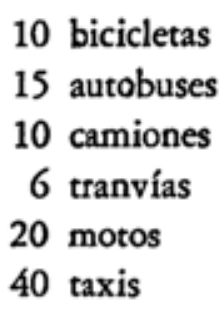

101 vehículos

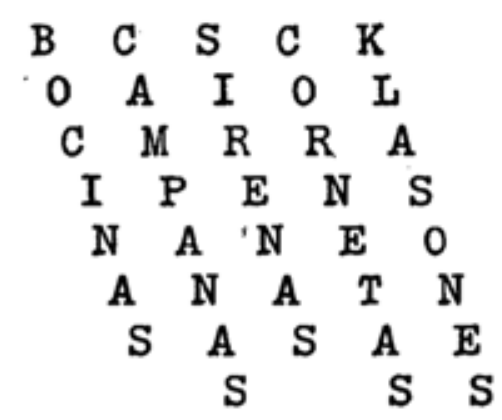

$\begin{array}{lllll}B & C & S & C & K\end{array}$

$\begin{array}{lllll}0 & \text { A } & \text { I } & 0 & \text { I }\end{array}$

$\begin{array}{lllll}C & M & R & R & A\end{array}$

$\begin{array}{llllll}\text { I } & \mathrm{P} & \mathrm{E} & \mathrm{N} & \mathrm{S}\end{array}$

$\begin{array}{lllllllll}A & \mathrm{~N} & \mathrm{~A} & \mathrm{~T} & \mathrm{~N}\end{array}$

$\begin{array}{ccccc}S & A & S & A & E \\ & S & & S & S\end{array}$

Figura 2. Poema sin obstaculos del tránsito ligero. Alfredo

Mario Ferreiro, 1969.

(...) marcha”.

¡Qué idea de reposo daría un rascacielo

acostado en el suelo!” (Ferreiro, 1969, p. 126).

Chucuchúcuchu

chás-chás,

Se mezclan las personificaciones con descripciones de personajes típicos de la ciudad, como ser el agente de tránsito. Estos son pintados en su movimiento. El aspecto cinético toma relevancia sobre cualquier otro.

"Danza con escenario de rascacielos, con sabor de asfalto,

con olor a cemento recién cuajado,

pebeteros de nafta,

irradiadores de electricidad." (Ferreiro, 1969:125)

Otro elemento característico es la utilización de onomatopeyas. Un ejemplo es la poesía "Tren en

2 En el Río de la Plata encontramos que un juego similar realiza el poeta argentino Oliveiro Girondo en Espantapájaros (2001). Esta publicación es de 1932, es decir, cinco ańos posterior al libro de Ferreiro. 
Por último, en relación a este texto aparecen dos elementos en donde lo americano se muestra con mayor fuerza. El primero es el humorismo. May Lorenzo Alcalá dice al respecto:

“... el uso que hace Ferreiro de las máquinas, íconos del futurismo, es humorístico, tal como puede notarse solo leyendo los títulos de ambos volúmenes, y no ideológico (...) Es decir, su intención no es introducir estos elementos de la modernidad en la poética, sino apropiarse de ellos para parodiarlos."(Lorenzo Alcalá, 2009, p.84)

Transcribo "El dolor de ser Ford" para que se pueda apreciar el elemento del humor en el texto:

\section{"EL DOLOR DE SER FORD}

¡Qué dolor debe dar ser siempre Ford! Ser Ford... que sólo valen por la pintura de afuera." (Ferreiro, 1969, p.128)

Y no ser un alado Packard,

un soberbio Lincoln,

un trompudo Renault,

o un ancho Cadillac.

Ser Ford, ser siempre hojalata.

Y que todos digan:

—Ahí va un Ford.

Como quien dice:

-Ahí va un cualquiera.

¡Y saber en lo íntimo

de las bujías y del carburador, que se es automóvil como los otros autos, y, a lo mejor, mejor..!

Qué dolor da ser hombre como los otros hombres y ser además, bueno,

y que todos nos créan un cualquiera juzgando por la apariencia externa.

¡Qué dolor debe tener el pobre Ford! Que anda como con vergüenza por las calles atontado por las sonrisas de klason de los autos petulantes

El Ford se presenta como una irónica metáfora del ser un cualquiera, en la que el humor está dado por la personificación y por una valoración social compartida hacia los automóviles. No todos los modelos y marcas son iguales y "todos" sabemos por qué, aunque "todos" juzguen "por la apariencia externa".

El otro elemento son los juegos con lo autóctono, a través de la inclusión de elementos de la naturaleza de la zona, donde la fuerza de la naturaleza pareciera entrar en tensión con la fuerza de la máquina. Un ejemplo es el poema "Este es el poema de los potros", del que citamos un fragmento en el epígrafe,. Otro poema, "Mar..", concluye de la siguiente forma:

"Mar: eres la boca enorme que pide la palabra y espera, en la asamblea del mundo, algún silencio para decirnos algo... Algo que debe ser la misma voz de Dios. 
Con tu garganta de luces,

tu paladar de cielo,

tus mandíbulas fuertes,

tus dientes de granítica piedra,

tu lengua hecha de aguas,

quieres — ¡oh mar! - decirnos algo.

Desde la noche inmensa de los tiempos corridos

estás chistando a los hombres

para que hagan silencio.

Y sin embargo...

¡Aquí nos tienes, cada vez con más ruidos!”(Ferreiro, 1969,

La fuerza de la naturaleza frente a la desobediencia de los hombres queda reflejada en el final de estos versos, en una tensión que no queda del todo resuelta, a pesar de la insistencia humana en aumentar el ruido.

En su segundo libro, $S R M$, queda aún más clara la relación ciudad, campo, mar y aire; incluso, esta distinción sirve para separar sus capítulos. En este sentido, Nelson Guerra afirma que en este libro es más claro el mundo simbólico de Ferreiro (Calvete y Guerra, 2018). El humor sigue presente, pero cambia de forma. Ya no es el humor casi ingenuo que podemos encontrar en el ejemplo de "El dolor de ser Ford".

“Agradecimiento" muestra una ciudad en vías de industrialización, donde ya no es todo felicidad y admiración a la máquina, sino que es una ciudad que devora, un andar que cansa, frente a la que, de todas maneras se intenta mantener la sonrisa. El proceso ya ha "mostrado la hilacha", ya no podemos ser tan optimistas:

“(...) Es hora de cenar.

Un poco sonrientes al sentirse cansados.

La hermana, el padre, los hermanos

han vuelto de ti, ciudad.

¡Gracias, mil veces gracias, por no haber saciado en ellos tu voracidaD!" (Ferreiro, 1930,

Vemos también como el humor está dado por la contradicción entre el agradecimiento a la ciudad y su voracidad. En contraposición a esta visión de la ciudad, el campo en esta obra gana amplitud. Andrade Genese resume el uso de este modo: "Predomina una mirada ingenua hacia el paisaje, atribuyéndose a lo que se ve elementos del imaginario popular."(Genese, 2009, p.42)

\section{Último vagón}

Volvamos a Rodolfo Kush. Hay en la poesía de Ferreiro un primer movimiento para intentar copiar, tomar, imitar una forma europea. Sin embargo, no puede escapar del "estar” americano. Como dice Kush: “(...) las formas culturales adquiridas en la esfera del dominio occidental, no tiene consistencia frente a lo americano" (Kush, 1986). La vitalidad se filtra en sus versos y hace aparecer este futurismo mestizo, especialmente a través de dos elementos. Por un lado, en las diferencias entre naturaleza-cultura, espacio natural-ciudad, no son tan claras como en el futurismo italiano, e incluso, a diferencia de este, y sobre todo en su segundo libro, Ferreiro no muestra una confianza absoluta en la modernización. Por otro lado, el humor aparece como la forma de mostrar esta desconfianza. Es por esto que, citando nuevamente a Kush, "Una estética de lo americano no puede reducirse a un análisis de las formas y de lo dado porque nada de esto tiene real consistencia entre nosotros" (Kush, 1986).

\section{Referencias}

Andrade, G. (2009). La imágenes de Alfredo Mario Ferreiro, en Rocca, Julio (ed.) Alfredo Mario Ferreiro: una vanguardia que no se rinde, Uruguay: Comisión Sectorial de Investigación Científica.

Borges, J. (1997) .El hombre que se comió un autobus en Revista Sintesis, 6.321-322.

Calvete, A. y Guerra, N. (2018) "El Futurismo de Alfredo Mario Ferreiro", Transmisión de programa Vivencias, 18/05/2018 por CX28 Radio Imparcial 1090 AM, https://www.youtube.com/watch?v=T6iPGq9JBpE, Fecha de consulta: 15 de noviembre de 2018.

Calvete, A. y Guerra, N. (2018) "Se ruega no dar la mano", Programa emitido el 25/05/2018 por CX28 Radio 
Imparcial 1090 AM, https://www.youtube.com/ watch?v=biWPbvg7myc, Fecha de consulta: 15 de noviembre de 2018.

Ferreiro, A. (1927). El hombre que se comió un autobús (Poemas con olor a nafta). Montevideo: La Cruz del Sur.

Ferreiro, A. (1969). El hombre que se comió un autobuis (Poemas con olor a nafta). Montevideo: Ediciones de la Banda Oriental.

Ferreiro, A. (1930). Se ruega no dar la mano (poemas profilácticos a base de imágenes esmeriladas). Montevideo: Cartel.

García Sedas, P., Torres-García, J. y Barradas, R. (2001). Un diálogo escrito: 1918 -1928. Uruguay:Parsifal.

Girondo, O. (2001). Espantapájaros (al alcance de todos). Buenos Aires: Losada.

Kusch, R. (1986). Anotaciones para una estética de lo americano, Identidad. I, 6-20.

Lorenzo Alcalá, M. (2009). La esquiva huella del futurismo en el Río de la Plata. A cien años del primer manifiesto en el Río de la Plata, Buenos Aires: Patricia Rizzo.

Rocca, P. (2009). La máquina y el tiempo. Alfredo Mario Ferreriro entre la novedad y la historia en Rocca, P. (Editor). Alfredo Mario Ferreiro: una vanguardia que no se rinde.

Rocca, P. (2003), Marinetti en Montevideo: idas y vueltas de la vanguardia"en Cuadernos hispanoamericanos En algunos casos incluso propone al lector juegos de lectura, como el siguiente: l final de estos versos. secuencian a los cost. 631, 105-120.

Sylvia S. (2014), Filippo Marinetti en la Argentina. en Bruno P. (Coord.) Visitas culturales en la Argentina, 1898-1936. Buenos Aires : Biblos.

Vasseur, Alvaro A. (1955). Poeta milanés, calvo y 'fundador de escuela’ / treinta años. En AAVV, Colección de Clásicos Uruguayos, Biblioteca «Artigas», Todos los cantos: Montevideo. 